\title{
- Surveillance \& society \\ 'I had no credit to ring you back': Children's Article strategies of negotiation and resistance to parental surveillance via mobile phones
}

\section{Carol Margaret Barron}

Dublin City University, Ireland.

carol.barron@dcu.ie

\begin{abstract}
The monitoring of children in time and space, from a distance via mobile phones, is a phenomenon never experienced in previous generations. Indeed, as frequently recited, the increased protection of children by monitoring them is a central characteristic of modern childhood (Rasmussen 2004; Qvortrup 1993) and the effects of this are not yet known. Equally, our understanding of how children in middle childhood ( $8-12$ years) negotiate and or resist this monitoring is unclear. This paper seeks to add to the emerging body of knowledge from an anthropological perspective on the strategies employed by children in middle childhood to negotiate and resist the monitoring and surveillance of their physical selves in time and space using mobile phones predominantly. I suggest that the mobile phone can be transformed by children into a highly efficient device to enable them to both negotiate and resist surveillance thus increasing their autonomy and independent mobility. Children are not passive recipients of parental surveillance and power, rather they are increasingly playing an active role in negotiation with parents and actively resist monitoring of their everyday lives.
\end{abstract}

\section{Introduction}

\section{Surveillance and Childhood}

The increasing use of surveillance methods and software to monitor and track children in both time and place reflects a global trend (Rooney 2010). At the societal level it is becoming the norm to have CCTV available in public places designed for children such as playgrounds and parks and at a local level in crèches and schools. Green (2002) tells us that mobile phones have brought surveillance, traditionally associated only with the state and corporate bodies, into the realm of individual's personal relationships, such as between parent and child. This in effect normalises the perception that all children should be accessible and accountable to others at any time and place. Mobile phones as a mechanism for surveillance are a relatively new phenomenon; available since the early to mid-1980s, yet within three short decades they have become a fixed feature of children's everyday worlds with a plethora of functions, of which the monitoring and surveillance of children by their parents as opposed to societal surveillance specifically is gaining more and more prominence. A quick trawl of the internet will inundate the viewer with multitudes of companies and software applications available for purchase by parents for use on children's mobile phones to monitor them in time, space and their actual use of mobile phones. Even the brand names of these applications allude to the surveillance and monitoring of children, e.g. 'My Mobile Watchdog'. 
From the emerging research on surveillance however, we recognize that surveillance has differing facets; it is no longer just about discipline and control, but is used or perceived as a form of 'care' as well, (Rasmussen 2004; Rooney 2010). Marx and Steeves (2010) explain that parents are encouraged to buy surveillance technologies to keep children 'safe'. As well as a lesser prominence on parental convenience and freedom, surveillance is primarily promoted as a required tool of responsible and caring parents. For example, the Mobile Spy ${ }^{1}$ webpage explains how they appreciate that parents feel they must give their children a mobile phone so they can contact them anytime but MobileSpy themselves understand that this comfort is overshadowed by children then having access to inappropriate websites and unsupervised texting or chatting. They claim to have the solution - their product, which they assert 'could be the most valuable tool in a parent's modern day arsenal... to keep [the child] safe'. We do not yet know the consequences of this caring and controlling surveillance and viewed in this light, the monitoring and surveillance of children's mobility is not that clear-cut (Fotel and Thomsen 2004).

\section{The rhetoric of 'risk reduction' in a risk adverse society}

Life involves risks, but Rooney (2010) argues convincingly that the ways in which surveillance technologies are used on children appear to aim at achieving a risk-free environment, with 'risk-reduction or indeed 'risk avoidance' put forward as a worthy goal. GPS tracking systems in mobile phones for example are also promoted as a general parental tool, aiming to provide reassurance to parents that they will always know where their child is. The increasing encouragement of these forms of surveillance as 'normalised' responses to everyday risks reveals how the efforts to monitor and control children using such technologies aims to leave childhoods as 'risk free' which I suggest is both unrealistic and unachievable. I suggest that the 'risk reduction' rhetoric underpinning much of the monitoring and surveillance of children using mobile phones is a reflection of the 'risk adverse' society(s) in which many of us live. Indeed, Livingstone (2002) argues that children need opportunities to interact with the world without being monitored to assist in the development of personal autonomy and independence. Despite the proliferation of differing products available to parents to both monitor and conduct surveillance at a distance on children that were very briefly alluded to above, one must voice a word of caution. None of the parents in the fieldwork settings for this research currently employed any of these 'products', rather they monitored Irish children in middle childhood in their lived worlds in time and space through texting and phone calls. One must question how much surveillance and monitoring using additional technology to the mobile phone is actually being used by parents, and is there a difference within and across differing national borders? More detailed and specific data on these questions would be beneficial to understand the possible outcomes of such monitoring and surveillance on children and within childhood more widely.

\section{Surveillance of children using mobile phones}

There is an extensive literature in relation to parent-child and parent-young person relationships, particularly in relation to monitoring and supervision, surveillance, independence and autonomy (Kerr, Stattin and Trost 1999; Stace and Roker 2005). There is a growing literature on the role of technologies in the lives of young people and families. Much of it focuses on how individuals and families use the internet (for example Holloway and Valentine 2001; Kerawalla and Crook 2002; Livingstone 2002). There is a smaller but growing body of work examining young people's use of mobile phones which focuses predominantly, though not exclusively, on teenagers or young people. Ling's $(2000,2003)$ research explored young people's use of mobiles in their everyday lives, and its effects on families. Similarly, Ito, Okabe, and Matsuda (2005) have reported how mobile phones have become a key part of social and personal lives in Japan. In Fotel and Thomsen's (2004) work on the surveillance of children's mobility they found that parents keep track of their children's position in space by making the child call during the day to tell the parent where they are and that monitoring children's mobility via a mobile phone appears to give some parents a feeling of control, thus seeming to minimise their risk perception, rather than the risk itself. Campbell (2006) examined mobile phone use and advertising with teenage girls. Williams and

1 http://www.mobile-spy.com/mobile-phone-monitoring.html 
Williams (2005) examined the increasing significance of the mobile phone in the way teenagers negotiate spatial boundaries with their parents. Devitt and Roker (2009) explored the role of mobile phones in communications between young people (11 - 17 years) and their parents, and Bond (2010) researched children's perceptions of the impact of the mobile phone on relationships in their everyday lives. The majority of research described above was conducted with young children and parents and as yet the views and experiences of children in middle childhood are largely unknown with the noticeable exception of Valerie Steeves' (2013) work on Canadian children's life online, which does address mobile phone ownership and use in middle childhood.

Let us look at children's play worlds and 'risk', children today as with previous generations enjoy an element of 'risk taking' in their play and games as opposed to 'risk-avoidance'. This is not a new phenomenon, indeed the famous portrayal of 'Children's Games' painted by the Flemish artist Pieter Brugel in 1560 provides a useful baseline from which to measure the survival, loss, and transformations of risk taking behaviour within children's play over 450 years, such as his image of a child disturbing a bee hive by prodding it with a hooked stick. The normality of risk taking behaviour in children's play does continue in various forms of play today (e.g. bouncing on large sized trampolines without an enclosure net). However, cultural attitudes to risk taking have changed. With a more litigation conscious culture, many designers of modern playgrounds consciously remove any 'risk' from their playground designs (Stephenson 2003) This has led to the development of so called 'fun free' playgrounds (Barron 2011a amongst others). Tom Gill further argues in 'No Fear; Growing up in a risk averse society' (2007) that childhood is being undermined by the growth of risk aversion and its intrusion into every aspect of children's lives, specifically their play worlds, and that this risk aversion restricts children's play, limits their freedom of movement, corrodes their relationships with adults, and constrains their exploration of physical, social, and virtual worlds.

Nihlén Fahlquist (2013) suggests that what used to be called play is now termed unsupervised children's activity and treated as a risk. Parental responsibility is associated with supervising one's children (Furedi 2006). When children occupy public spaces for their play Gill Valentine argues that, 'Unable or unwilling to trust their children to manage their own safety in public places, most parents actively control and restrict their children's use of space' (2004: 55-6). Malone (2007) refers to children born after 1991 as 'Generation Z'; that is, children born in the age of terrorism, mobile phones, internet, Facebook, blogs and the wiki, and she accuses parents of 'bubble-wrapping' (Cadzow 2004) or being over protective of their children, the impact of which has led to a dramatic decrease in children's independent mobility and restricted use of space. This paper seeks to add to the emerging body of knowledge on the strategies employed by children in middle childhood to negotiate and indeed resist the monitoring and surveillance of their physical selves and their independent mobility in time and space using mobile phones from an anthropological perspective.

\section{Changes in children's play}

Children's play, like surveillance technology, is not static and there have been significant changes to children's play and their play spaces over time which I will briefly summarise. Over the past century and a half there has been a gradual, long-term shift in the 'spaces of childhood', from outdoors to indoors, from woods, fields and streets, to back and front gardens, bedrooms and commercial and other formal play sites (Burke 2005; Rasmussen 2004; Skelton and Valentine 1998). There has also been a shift in playmates, from family members, including siblings and cousins, to the peer group, and especially same-sex peers, as well as an increase in small group and solitary play, with geographical proximity no longer the predominant way that play groups formed. At the same time, there has been a shift in the material culture of childhood with toys being marketed directly to children (Mintz 2009). The most important trends have been a decline in intergenerational amusements, an increase in sedentary, isolated play (Sutton-Smith 1997), electronically mediated play (Kline 2004; Tapscott 1998), and a decline in wholly unsupervised, free, unstructured play (Meire 2007). But Mintz (2009) argues these trends have developed more slowly 
and incrementally than many assume, and their roots lie largely in demographic developments, not in misplaced cultural values. Similar to all cultures, children's culture itself is not static. In every historical era, diverse children's cultures coexist, varying according to children's age, class, ethnicity, gender, location, and race. Children's culture today can be understood as a response to a specific social and cultural environment, in this case societies dominated by technology, of which a subset is utilised by parents, for example mobile phones to ensure they 'care' for their children by monitoring them in time and space utilizing mobile phones.

\section{Parent's use of mobile phones as a surveillance tool}

Parents' remote control of children can be performed in multiple ways, and the mobile phone is one of the more common surveillance technologies available that can assist them in tracking, monitoring and controlling children in time and space. Within the research findings described in this paper, parents did not use GPS tracking or dedicated software applications on their children's mobile phones; rather the surveillance was undertaken by mothers predominantly using text messages and / or phone calls.

\section{Fieldwork setting and research methodologies}

The fieldwork took place in Ireland which is a small country on the periphery of north-western Europe. The climate in Ireland is temperate, however rainfall is very common, with some parts of the country getting up to 275 days of rainfall annually. During the autumn and winter it gets dark between 4:00 to $4: 30 \mathrm{pm}$ and this lasts from November through to the end of February. Both the climate and the dark evenings have an effect on children's independent mobility, and thus, their parents' monitoring of them in time and space. Rathvarna is the pseudonym for the town in which the fieldwork took place and it is situated in Kildare which borders the capital of Dublin on its western border; Rathvarna is approximately twelve miles from the centre of Dublin city and was historically a market town based on the banks of a river. It mirrors the growth of many such towns which are within commutable distance to Dublin and it is classified as an urban setting. In the last decade Kildare had the second fastest growing population in the country; the population is 19,537 (Central Statistics Office 2012). This growth was due to the higher cost of housing in the capital and families moving out to more affordable housing in the suburbs with the availability of good transport links to Dublin via public transport and major motorways that enable adults to commute to their work in the city. The majority of families living in Rathvarna were not born there but migrated to the area for purposes of work, study and / or because of the lower cost of accommodation (Waddington 2000). Therefore very few of its inhabitants (adults or children) have any extended family within the town, similar to many 'commuter belt' settings throughout Ireland and elsewhere. The built environment is a mix of the old and new. Old narrow side streets, with (and without) narrow paths lie in close proximity to insulated housing estates.

The town has seen a rapid expansion of housing over the last two decades which has resulted in children's increasing removal from natural habitats (Hart 1997; Moore 1995). More than 30 multiple housing developments/estates were built between 1992 and 2006 but predominantly from 2001 - 2005 to accommodate the town's growing population. Most of the children of Rathvarna reside in one of these housing estate settings. Moore and Young (1978) discuss the importance of housing estate design and residential location in restricting children's play opportunities but also highlight how each estate creates opportunities for play, irrespective of the formally designated play provision within the estate. None of the estates in Rathvarna have any formal communal seating areas or fixed play equipment. The housing estates predominantly have one access road into the estate with various tributaries off this road leading into cul-de-sacs which are composed of houses usually in a circle or semi-circle formation, overlooking a communal green area and the same road is used to exit the estate. 


\section{Methodology}

As ethnography attempts to place the participants' own perspectives centrally (Hammersley and Atkinson 2007), I suggest that it is eminently suited to examine the lived experiences of children in relation to what and where they play and the monitoring of their use of time and space. In addition, a child-centred anthropology views children as the best informants of their own lives and worlds (Montgomery 2005). Children are competent social actors and therefore need to be involved in the construction of new understandings about their worlds. To this end, participatory data collection techniques such as visual photography to generate their own data on and about their play and play spaces alongside the more traditional methods of participant observation in two single-sex school settings and the housing estates over a school year were employed. As the focus of the research was on children in middle childhood, participant observation took place in $4^{\text {th }}, 5^{\text {th }}$ and $6^{\text {th }}$ classes (aged 8/9 -12 years) in both schools. Ethical approval for the research was sought and received prior to the commencement of the study. Written informed consent was received from the parents of all children in both schools and written informed assent from the children who took part in the visual techniques phase of the study.

\section{Visual anthropology}

The collection of image-based data in the form of photographs has a long tradition within anthropological and ethnographic studies. The interest in the visual has transferred to childhood studies in various disciplines and there is a rapidly growing body of research which utilises visual images as a data collection tool with children (see for example Sharples et al. 2003; Burke 2005; Nic Gabhainn and Sixsmith 2006; Kaplan 2008; Barron 2011b). The use of photography by children as a method of data collection enables data to be generated ' $b y$ ' rather than 'of' children (Nic Gabhainn and Sixsmith 2006). This differentiation is important as the use of cameras by children is a move towards providing insight into the insider's view of the world, the emic perspective (Barron 2011a). This in turn also allows the child's 'voice' to record and capture what is important to them, rather than the adult recording images and imposing adult interpretation of importance. To account for seasonal variation in the places where children like to play, disposable cameras were distributed in the winter and following summer. In total 60 children took part in this part of the research, 32 girls (21 in the winter and 11 in the summer) and 28 boys (14 in the winter and 14 in the summer). Girls ranged in age from 9 years 3 months to 12 years. $(\mathrm{M}=10.99)$, the boys ranged in age from 9 years 10 months to 12 years 9 months $(\mathrm{M}=10.99)$. They produced 1028 images of play spaces, places, activities and play objects of which 940 were included in the study. Visual content analysis, that is, an 'empirical and objective procedure for quantitatively recording visual representations using reliable and explicitly defined categories' (Bell 2001: 14) was used as an appropriate technique, especially when approaching a large number of images in a consistent manner (Rose 2001).

\section{Photo elicitation discussions}

Eleven photo elicitation group discussions were held after the children had collected their pictures and reviewed them. The group interviews lasted between 40 to 60 minutes. For the purposes of this study, photo elicitation was used as a data gathering technique where the children's own photographs were introduced as the main discussion points for the interviews as the aim is to explore the significance or meaning of the images with the participants (Prosser 1998). This places the child in the role of the expert not the researcher; the child has expert knowledge that the researcher uncovers through the medium of photo elicitation, which marries well with the view of Douglas Harper who suggests that that photo elicitation should be regarded as 'a postmodern dialogue based on the authority of the subject rather than the researcher' (2002: 15). The photo elicitation group discussions took place as soon as possible after the pictures were taken to aid children's recollection of taking the particular images and the meanings behind them. This also assisted in the accurate coding of the images. All group discussions were tape recorded for accuracy, transcribed verbatim and analysed using content analysis. The quantitative technique of visual content analysis provided 'a background map of a domain of visual representation' (Bell 2001: 27) and was supplemented with the triangulation of the data analysed from the photo elicitation group discussions as well as field notes from the participant observations with the children in schools and the local 
neighbourhoods to give a more in-depth understanding. Whilst pseudonyms are used for the children's names in this paper, their photographs are used. Children are active agents in constructing their lived worlds, they have actively reconstructed their worlds for adults to appreciate using their everyday play worlds; not to 'give voice' or accurately portray their visual worlds (James 2007) places children in a very passive, non-participatory role which does not fit well with the new childhood studies whose philosophy underpins this research.

\section{Findings}

\section{Monitoring of children and their play spaces}

As previously mentioned, the increased protection of children by monitoring them in time and space is a central characteristic of modern childhood (Rasmussen 2004). Societal and cultural changes that face Western society today in relation to parental fears for their children (stranger danger, increased road traffic, environmental barriers and so forth) are now well known. But apart from the home and school, where do children in middle childhood live their lives? Play in public spaces, such as streets and housing estates, is much more important to children than adults realise. Yet, with the exception of research in children's geographies, the research on 'street play' is surprisingly absent from the literature on children's play; this is despite the knowledge found time and time again that children like to play close to their home in their own neighbourhood (Meire 2007; Barron 2013). Ireland has become an increasingly globalised society yet the importance of the local is apparent within late modernity. Sixty children $(28$ girls and 32 boys) recorded 940 images of what and where they played over the winter and summer. To allow for seasonal variation and the physical spaces they occupy are:

- 472 images recorded in the home

- 230 in the housing estate

- 238 outside the housing estate

Whilst in the home, children in middle childhood are under the direct supervision of their parents, the 238 images recorded outside of the housing estate were predominantly taken at sports venues (fields and sports clubs), after school activities (gymnastics, horse riding, dance class) and the children needed to be chauffeured there again under the direct supervision of a parent or other adult. The remaining physical spaces in which children live their lives and play was within the immediate space of the housing estate (just under 50 per cent of all outdoor play spaces). See Table 1 for a representation of boys' and girls' housing estate play spaces and places.

BOYS GIRLS

\begin{tabular}{|c|c|c|c|c|c|c|c|c|c|c|}
\hline & Winter & Summer & Sub total & $\%$ & Winter & Summer & Sub total & $\%$ & Total & $\begin{array}{c}\text { Overall } \\
\%\end{array}$ \\
\hline Back Garden & 18 & 30 & 48 & 28.40 & 20 & 41 & 61 & 52.59 & 109 & 38.25 \\
\hline Road in H. Est. & 0 & 42 & 42 & 24.85 & 20 & 6 & 26 & 22.41 & 68 & 23.86 \\
\hline Front Garden & 6 & 23 & 29 & 17.16 & 8 & 14 & 22 & 18.97 & 51 & 17.89 \\
\hline $\begin{array}{l}\text { Green area in } \mathrm{H} \text {. } \\
\text { Est. }\end{array}$ & 2 & 40 & 42 & 24.85 & 2 & 2 & 4 & 3.45 & 46 & 16.14 \\
\hline $\begin{array}{l}\text { Cul-de-sac in } \mathrm{H} \text {. } \\
\text { Est. }\end{array}$ & 0 & 3 & 3 & 1.78 & 0 & 3 & 3 & 2.59 & 6 & 2.11 \\
\hline Front driveway & 0 & 5 & 5 & 2.96 & 0 & 0 & 0 & 0.00 & 5 & 1.75 \\
\hline Total & 26 & 143 & 169 & 100.00 & 50 & 66 & 166 & 100.00 & 285 & 100.00 \\
\hline
\end{tabular}

Table 1: Boys and girls outdoor play spaces in the Housing Estate 
This research supports the finding that children in middle childhood ( $8-12$ years) play close to their home and thus monitoring children by parents using mobile phones is of limited value. Indeed parents employ alternative monitoring systems, such as restriction of movement within these play spaces, as Harry and Terence explain:

Harry: I'm not allowed outside my estate. I will be soon, so that's where I play [in the estate] there's lots of trees in my estate.

Carol: $\quad$ You will be allowed outside the estate soon?

Harry: My mam just says I'm old enough now but she has to see that she can get my trust. She says that she knows that I'm old enough; she just wants to make sure that I'm responsible enough to actually go out and watch the cars on the road and stuff.

Carol: What about yourself Terence?

Terence: No, I'm not allowed out of my estate but I'm allowed to go around it. [10 and 11years]

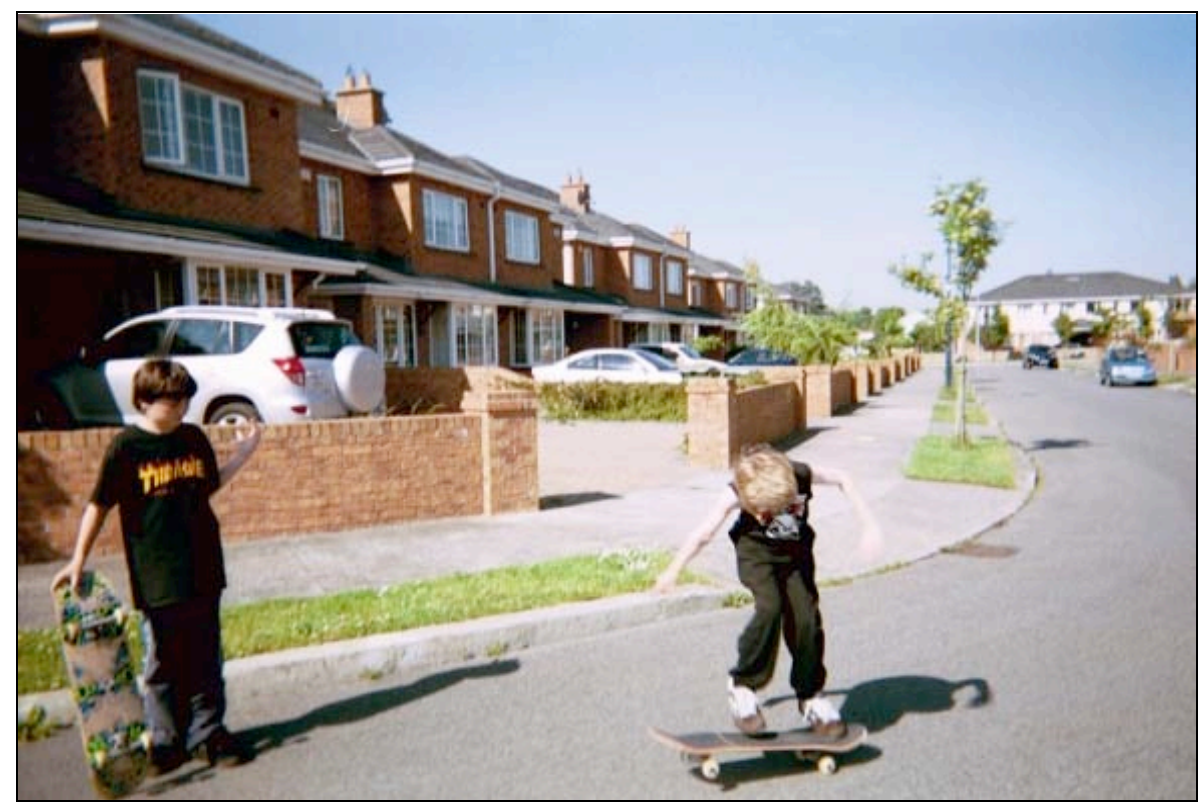

Image 1: Children playing in their housing estate

Children's ability to move geographically outside of their immediate housing estate depended on multiple factors; their chronological age, the location of their home, proximity to a busy road or narrow footpath, 'stranger danger' fears, parents' beliefs about individual child's competence with traffic, and so forth.

\section{'For emergencies'}

All of the children in the $5^{\text {th }}$ and $6^{\text {th }}$ classes ( $8-12$ years) had mobile phones and approximately a quarter of the 8/9 year olds in $4^{\text {th }}$ class, similar to the findings of Steeves (2013). All the children had to keep their mobile phones in their school bags during school hours but were not allowed to turn the phone on, indeed it is against the school rules to have their phones switched on or on their person as Aisling explains, 'Like if your phone is in your pocket, even if it's off and the teacher sees it, she takes it off you' [12 years]. In both schools a practice of confiscation is used for transgressions by children of the rules in relation to mobile phones. Outside of the school day, they kept their mobile phones on their person. When I asked why they brought their phones to school when they could not use them, the consistent and repeated answer from the children was 'for emergencies'. 'My mum makes me bring it for emergencies', 'Emergency use only'. I am still unclear as to what constitutes an 'emergency' and the children were not sure either but 
they recounted stories of their mothers calling them to make sure they had arrived home after school or arrived at their organised after school activity and so forth. 'Emergencies' would thus appear to be a justification for parents to give children mobile phones and to monitor the child in time and space which appears to provide some parents with the feeling of control and thus seems to minimise their risk perception. The children however were very clear that they view the mobile phone as a form of communication, specifically textual as opposed to oral communication, that is, 'mobile phones are for texting my mates' [Tony 10 years].

\section{Strategies of negotiation}

While parents, though mothers predominantly, use the mobile phone in part as a method of monitoring at a distance, children employ strategies of negotiation. The monitoring of children's mobility unfolds in an on-going dialogue between parents and children, as the extract below demonstrates:

Gus: I tell my ma to text me, not ring me, when I'm with me friends.

Carol: Why text only?

Gus: Because it's embarrassing you know, it's embarrassing if your mother checks up on you, if she texts then they don't know it was her [who texted] that's O.K.

Carol: So if you're with your friends does your mum ring or text you?

Gus: She texts me. [age 10 years]

Children actively engage in planning their own movement and are not just objects of their parents' remote control. Many of the children throughout the year's fieldwork recounted getting their parents to text them rather than call. Discussions about the power relationships between children and parents always have the child as powerless or less powerful (Lynch and Lodge 2002; Christensen 2004). However family power relationships are not static, and children clearly demonstrate the ability to negotiate with their parents in relation to the monitoring of their everyday lives. Texting is a modern day example of a negotiated compromise between parent and child. It allows the parent to monitor their child if they desire to without direct oral communication and is also viewed more positively by children, as explained by Gus in the example above. Williams and Williams (2005) examined child / parent negotiation with young people (15 and 16 year olds). They found that young people see themselves gaining a degree of empowerment from the mobile phone and that the mobile has in fact become a significant facilitator of negotiations between parents and young people. Children are increasingly skilful negotiators by on-going renegotiation in their relations with their parents. Nevertheless, parents are using the mobile phone to enter into their children's time and space as an 'absent other', and see this as a means of extending parental authority and control (Williams and Williams 2005).

\section{Strategies of resistance}

Both boys and girls recounted how they resisted the restrictions on their mobility using avoidance strategies, as with Sorcha in the extract below:

If my mum rings me and I am up at Lauren's [where she is not allowed to go on her own] I don't answer it and then pretend that it was on silent like and I did not hear it like [9 years].

Josh (aged 11 years) recounts another frequent strategy of resistance used by the children which is that 'the battery was flat'. This strategy included the deliberate as well as the accidental failure to recharge the mobile phone to avoid monitoring and the falsification that the mobile was uncharged when that was not true. The deliberate avoidance of parental monitoring has also been found in research with older children. For example, Devitt and Roker (2009), whilst exploring the role of mobile phones in communications between young people $(11-17$ years) and their parents, report that young people acknowledged they avoid contact with their parents by not answering their phones or not having their phones charged. Both 
boys and girls recounted stories of telling their mothers that, 'I forgot to turn it on after school' or, 'I had no credit to ring you back', or 'it was on silent and I did not notice'. The avoidance of parental monitoring with the strategy of 'I had no credit to ring you back' was very common in middle childhood, perhaps because they did frequently run out of credit and thus it was viewed as a very justifiable and believable excuse to employ in their avoidance of parental monitoring.

Some children did deliberately give false information about their physical location when parents texted them asking where they were:

I text her back and say I am just outside on the green when really I am in Tom's house.

[Paul 12 years] [in the next housing estate where he is not allowed without permission]

Williams and Williams (2005) point out that parental 'authority-at-a-distance' is in some senses illusionary, since parents have little way of ascertaining the exact location of their children, especially when monitoring using text or phone calls only. While children deliberately thwart parents' attempts to monitor their mobility and are sometimes less than truthful about their whereabouts, none of the children, when discussing the strategies they employ to resist their parents' surveillance of their locations with the mobile phone went any significant geographical distance from the home (less than $1.2 \mathrm{~km}$ ): it was predominantly to visit friends in neighbouring estates, go to a local space not 'allowed' by their parents or to go to the sweet shops on the way home from school.

\section{Texting language as a strategy of resistance to monitoring}

The language of texting has developed out of the need to compress words sent by mobile phones due to limitations of space. Furthermore, conducting a conversation in real time also calls for speed in the writing of the message. The language used in messaging by the children is markedly informal and in some ways reminiscent, according to Alberto-Andres (2004), of the language used in quickly scribbled notes that were passed from child to child in the classroom setting in previous generations. While finding a very similar use of language in the children's mobile phone texts as Albero-Andres (2004) did, e.g. 'heya wdc wyu2' (Heya what the craic, what you up to?) ; 'cuL8er' (see you later); 'up2u' (up to you); 'were r u' (where are you?); 'tnkz' or 'tanks' (thanks); kwl (cool); clas (class - meaning brilliant, great), I also noticed the emergence of further compression of words into single letters even when space is not the issue. I suggest this is due to the speed of real time conversation coupled with the use of a textual language which may be virtually indecipherable to parents, such as the following; 'lol' (laugh out loud), ' $\mathrm{k}$ ttyl' (o.k., talk to you later), 'ily' (I love you), 'OMG' (Oh my God!), 'g2g' (got to go), 'y' (Why?). This further compression of written language was used both on its own, e.g. 'k' (o.k.) as a response to a text, or in combination with words that had already been compressed. See, for example, the text message below between Hannah and Orlaigh:

Orlaigh: heya hun wyu2 wde plz wb im reli bored [heya hun, what you up to? Please write back, I'm really bored]

Hannah: $\quad \mathrm{nm}$ jus on d laptop $\mathrm{r} u$ goin ta K8s party [nothing much, just on the laptop. Are you going to Kate's party?]

Orlaigh: prob f im alowd u [probably, if I'm allowed. You?]

Hannah: yeah cnt w8 hop il c ya dere [yeah can't wait, hope I'll see ya there]

Orlaigh: same g2g having mi dinner tty wen im done... ly x x x x x [same, got to go, having my dinner, talk to ya when I'm done, love ya kiss, kiss kiss, kiss, kiss]

Hannah: k ttyl [o.k., talk to you later]

End of textual conversation [Orlaigh and Hannah are both 12 years old]

The compression of words enables children to communicate with each other in almost real time. Texts are composed, sent, a response developed and delivered in seconds. This dance of texting communication 
moves back and forwards between two players very rapidly. Note in the example given how children incorporate culturally specific terms into the text using a single letter of the alphabet e.g. $\mathrm{c}=$ craic and wdc = what the craic?. The use of a question mark is not used in the written text but it is implied. The use of 'ya' does mean 'you' but can also be pronounced as 'ya' in Ireland, e.g. 'ya doing anything this weekend'. Children as young as 9 years have learned to transform and adapt written and verbal language into a format that is comprehendible to them and enables them to conduct textual conversations with their peers in virtual real time. Of course, the fact that this language may be incomprehensible to parents and other adults has similarities to children developing their own 'secret language' in previous generations, and can limit parents' ability to comprehend the texts even when they read them. The medium of texting can to some degree resist parental monitoring of children's text messages by virtue of the fact that they may find them difficult to decipher.

A final common strategy of resistance employed by both boys and girls, especially the 11 and 12 year olds, was to delete their text messages almost on a daily basis:

Orla: I delete my text messages all the time.

Carol: Why?

Orla: ‘cause like, it's my business, like its private and I don't want other people reading them.

This strategy of resistance is very similar to the strategy described by Livingstone (2002), where children deleted their web surfing histories and used a web tool of surveillance to their own end to avoid surveillance. Under the United Nations Convention on the Rights of the Child (UNCRC 1989), children have a right to privacy, yet despite this international treaty, children's right to privacy has not been broadly debated despite the current emphasis on privacy concerns regarding adults (Hanafin et al. 2010). Orla, at age 12 years, clearly articulates her desire for personal privacy. To achieve this goal she deletes her texts, an activity many of the children engaged in. This deletion of texts by children in middle childhood is not to prevent parents monitoring there texts, rather it is to prevent anyone (peer, parent, sibling etc.) monitoring them. Nihlén Fahlquist (2013) argues that there is a strong case for children's right to privacy; albeit not necessarily as wide-ranging as the adult equivalent and that it is reasonable that children have some private space. It is worth noting that whilst the term parent has been used in the preceding discussion on strategies of negotiation and resistance to monitoring, the children, both boys and girls, continuously and consistently referred to mothers in the monitoring role and not fathers.

\section{Non technological strategies to avoid surveillance}

Technology is not the only form of resistance to monitoring employed by children in middle childhood. Many of the older children, especially the girls, would take the family dog for a walk (see image 2). This enabled them to receive permission from their parents to leave the housing estate and increase their spatial mobility, to meet up with friends and socialise, as well as fulfil a desire to play with their pets. The girls, individually and collectively, understand that parents will give permission for increasing their spatial mobility if they are in groups and if they have animals with them, specifically dogs, and they negotiate very successfully with their parents to increase their independent mobility using the combination of collectives of children together with collectives of dogs. Again, similar to the strategies of resistance they employ with mobile phones, these strategies also give them more individual control over their location in space and served to increase their mobility. However, the physical location and environmental structures of their immediate surroundings determined how far they could go:

Rian: I walk the dog but I can't really go that far because if I go really out of my estate it's really going into the village kind of and the path up there is really narrow. [11 years]

Terence: Yeah if the dog took a few steps it could get run over. [12 years] 
Walking the family dog, an animal which may afford some physical protection and may give some parents a feeling of control, thus seems to minimise their risk perception. The children's mobility, however, remains restricted due to environmental facts such as narrow paths.

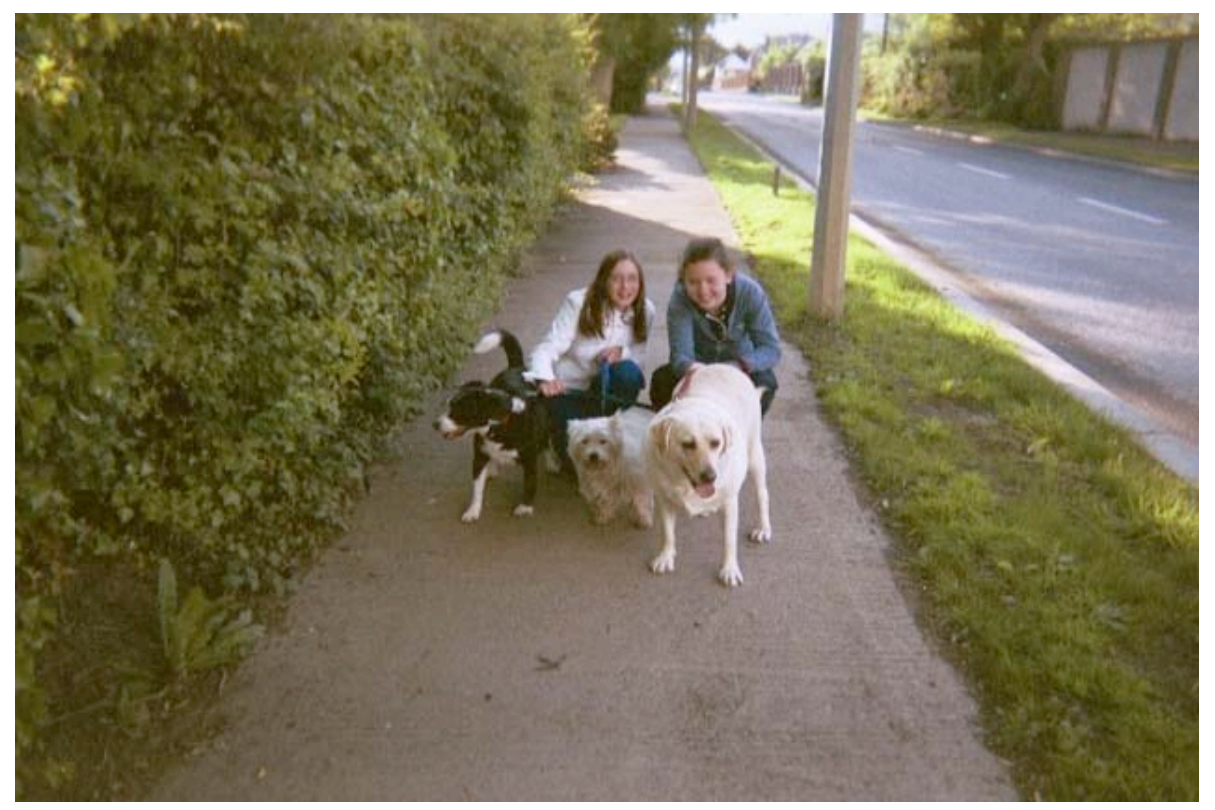

Image 2: Girls walking the family dogs

\section{Discussion / Conclusion}

Irish children in middle childhood are part of what Malone (2007) refers to as 'Generation Z'; that is, they have always lived in a world with mobile phones, the internet and social media sites, so called 'digital natives' (Livingstone 2002), although their parents have not. Today, technology provides parents with numerous opportunities to monitor children, one of which is the mobile phone. The substantial advantage of this technology is, of course, associated with safety, security, and easing parents' anxiety and fear. Moreover, the mobile phones can be used by parents to have a 'child care' role, answering 'where are you?', 'what are you doing' and 'who are you with?' Alongside the evolution in communication technologies is the 'bubble-wrapping' (Cadzow 2004) or over protection of children due to factors in the built environment, such as increased traffic and stranger danger fears, all of which has culminated in a dramatic increase in children's surveillance by parents and society more widely. This rhetoric of 'risk avoidance' or 'risk reduction' is becoming dominant not only in commercial cultures but also within academic fields and various government policies.

Yet children are not passive, powerless recipients of this surveillance; rather they tell us of their forms of negotiation and resistance to monitoring of their play spaces. Children's resistance to monitoring of their mobility in time and space unfolds in an on-going dialogue between parents and children (e.g. Gus's negotiation with his mother to text, rather than call him to identify his spatial location). While adults may use the mobile phone as an invisible surveillant device, children completely turned the mobile phone to their advantage in resisting this surveillance through a variety of means (e.g. using text-only to communicate with parents enabled the children to say they were in a specific, special location when this was not always truthful). Indeed, the mobile phone is quite possibly a mechanism employed by children in middle childhood to actually increase their spatial mobility, thus increasing their autonomy and independence, which are normal elements of child development. 
Not all surveillance of children in middle childhood and the resistance of this surveillance uses technology such as the mobile phone. Parental restrictions on children's mobility can restrict children very much in the local — the home and housing estate-however, it must be acknowledged that children like to play close to their home in their own neighbourhood (Meire 2007; Barron 2011a). Children appropriate, reproduce, and reinvent cultural and societal information; they do not simply internalise the society and culture in which they are growing up within, rather they are actively contributing to cultural production and change, as well as adapting and internalising the same information. This is apparent within their use of mobile phones to resist monitoring of their physical selves in time and space. Children share, negotiate, and create culture with each other and adults, thus making meaning anew (Corsaro 2005; Toren 2007) and they are agents of their own development and also in society. Yet, by being participants in society, like adults they are also constrained by existing social structures and dominant rhetorics.

A final work of caution and call for further research is that mobile phone monitoring and surveillant technology has advanced much faster than researchers can keep up with. Whilst there is a proliferation of products available to parents, we do not yet know what the uptake of these products are. Do parents make their decisions to purchase (or not) these technologies based on children's gender, their age, where they live? Are there cultural differences within and between nation states' uptake of these technologies at the macro and micro levels? Until we can answer these questions amongst others, the effects of monitoring and surveillance of children and childhood will remain unclear.

\section{References}

Albero-Andres, M. 2004. The internet and adolescents: The present and future. In: Toys, Games, and Media, eds J.H. Goldstein, D. Buckingham, and G. Brougere, 109-130. New Jersey: Lawrence Erlbaum Associates.

Barron. 2011a. Fun is a serious business: "Sameness" and "difference" in the play spaces, play activities and toys of Irish children in middle childhood. Unpublished PhD thesis. National University of Maynooth. Ireland.

- 2011b. Enabling children's voices in ethnographic writing: An evaluation of photographs by children as a data generating tool. Irish Journal of Anthropology 14(1): 32-39.

. 2013. Physical activity play in local housing estates and child wellness in Ireland. International Journal of Play 2(3): 220-236.

Bell, P. 2001. Content analysis of visual images. In: Handbook of Visual Analysis, eds T. Van Leeuwen, and C. Jewitt, 10-34. London: Sage Publications.

Bond, E. 2010. Managing mobile relationships: Children's perceptions of the impact of the mobile phone on relationships in their everyday lives. Childhood 17(4): 514-529.

Burke, C. 2005. Play in focus: Children researching their own spaces and places for play. Children, Youth and Environment 15(1): 27-53.

Cadzow, J. 2004. The bubble-wrap generation. The Sydney Morning Herald, 17 January; 18-21.

Campbell, R. 2006. Teenage girls and cellular phones: discourses of independence, safety and 'rebellion'. Journal of Youth Studies 9 (2): 195-212.

Central Statistics Office 2012. Census 2011 Volume 1 - Population Classified by Area. Dublin: Stationery Office.

Christensen, P. 2004. Children's participation in ethnographic research: Issues of power and representation. Children \& Society 18 (2): 165-176.

Corsaro, W. 2005. The sociology of childhood. 2nd ed. California. Pine Forge Press.

Devitt, K. and D. Roker. 2009. The role of mobile phones in family communication. Children and Society 23(3): $189-202$.

Fotel, T. and T. Thomsen. 2004. The surveillance of children's mobility. Surveillance \& Society 1(4): 535-554.

Furedi, F. 2006. The Culture of Fear Revisited. Continuum: London.

Green, N. 2002. Who's watching whom? Monitoring and accountability in mobile relations. In: Wireless world: Social, cultural and interactional issues in mobile technologies, eds B. Brown, N. Green and R. Harper. London: Springer.

Hammersley, M. and P. Atkinson. 2007. Ethnography, principles in practice. $3^{\text {rd }}$ ed. London: Routledge.

Hanafin J., T. Donoghue, M. Flynn, and M. Shevlin. 2010. The primary school's invasion of the privacy of the child: Unmasking the potential of some current practices. Educational Studies 36 (2):143-152.

Hart, R. 1997. Children's participation: The theory and practice of involving young citizens in community development and environmental care. London: Earthscan Publications Ltd.

Harper, D. 2002. Talking about pictures: A case for photo elicitation. Visual Studies 17(1): 13-26.

Holloway, S. and G. Valentine. 2001. 'It's only as stupid as you are': Children and adults' negotiation of ICT competence at home and at school. Social and Cultural Geography 2 (1): 25-42.

Ito, M., D. Okabe, and M. Matsuda, eds. 2005. Personal, Portable, Pedestrian. MIT Press: London. 
James, A. 2007. Giving voice to children's voices: Practices and problems, pitfalls and potentials. American Anthropologist 109(2): 261-272.

Kaplan, I. 2008. Being 'seen' being 'heard'; Engaging with students on the margins of education through participatory photography. In: Doing visual research with children and young people, ed. P. Thompson, 175-191. London: Routledge.

Kerawalla, L., and C. Crook. 2002. Children's computer use at home and at school: Context and continuity. British Educational Research Journal 28: 752-767.

Kerr, M., H. Stattin, and K. Trost. 1999. To know you is to trust you: Parents' trust is rooted in child disclosure of information. Journal of Adolescence 22: 737-752.

Kline, S. 2004. Learners, spectators, or gamers? An investigation of the impact of digital media in the media-saturated household. In: Toys, Games, and Media, eds J.H. Goldstein, D. Buckingham, and G. Brougere, 131-156. New York: Lawrence Erlbaum Associates.

Ling, R. 2000. 'We will be reached': The use of mobile telephony among Norwegian youth. Information Technology and People 13 (2):102-120.

-2003. Fashion and vulgarity in the adoption of the mobile phone among teens in Norway. In: Mediating the human body: Technology, communications and fashion, eds L. Fortunati, J. Katz, and R. Riccini, 93-102. Milan: Lawrence Erlbaum.

Livingstone, S. M. 2002. Young people and new media: Childhood and the changing media environment. London: Sage Publications.

Lynch, K. and A. Lodge. 2002. Equality and power in schools: Redistribution, recognition and representation. London: Routledge Falmer.

Malone, K. 2007. The bubble-wrap generation: children growing up in walled gardens. Environmental Education Research 13(4): 513-527.

Marx, G. and V. Steeves. 2010. From the beginning: Children as subjects and agents of surveillance. Surveillance \& Society 7 (3/4): 192-230.

Meire, J. 2007. Qualitative research on children's play; A review of recent literature. In: Several Perspectives on Children's Play, eds T. Jambor, and J.V. Gils, 29-78. Antwerpen: Garant.

Mintz, S. 2009. Children's culture. In: Re-Staging Childhood Conference. Utah, USA: Utah State University. August 6-10.

Montgomery, H. 2005. Gendered childhoods: A cross disciplinary overview. Gender and Education 17(5): 471-482.

Moore, R. 1995. Children gardening: First steps towards a sustainable future. Children's Environments Quarterly 12 (2): $222-232$. - and D. Young. 1978. Childhood outdoors: Toward a social ecology of the landscape. Children and the Environment 3: 83-130.

Nic Gabhainn, S., and J. Sixsmith. 2006. Children photographing well-being: Facilitating participation in research. Children and Society 20(4): 249-259.

Nihlén Fahlquist, J. 2013. Responsibility and privacy: Ethical aspects of using GPS to track children. Children and Society. Published online: $18^{\text {th }}$ April 2013. DOI:10.1111/chso.12016

Prosser, J., ed. 1998. Image based research: A sourcebook for qualitative researchers. London: Routledge Falmer.

Qvortrup, J. 1993. Nine theses about childhood as a social phenomenon: An introduction to a series of national reports. Vienna, Austria: European Centre for Social Welfare Policy and Research.

Rasmussen, K. 2004. Places for children - children's places. Childhood 11 (2): 155-173.

Rooney, T. 2010. Trusting children: How do surveillance technologies alter a child's experience of trust, risk and responsibility? Surveillance \& Society 7 (3/4): 344-355.

Rose, G. 2001. Visual methodologies: An introduction to interpreting visual objects. London: Sage Publications.

Sharples, M., L. Davison, G. Thomas, and P. Rudman. 2003. Children as photographers: An analysis of children's photographic behaviour and intentions at three age levels. Visual Communication 2(3): 303-330.

Skelton, T. and G. Valentine. 1998. Cool places: Geographies of youth cultures. London: Routledge.

Stace, S., and D. Roker. 2005. Monitoring and supervision in 'ordinary' families. York: Joseph Rowntree Foundation.

Steeves, V. 2013. Young Canadians in a wired world, phase III: Life Online. Ottawa: MediaSmarts. Available at: http://mediasmarts.ca/research-policy

Stephenson, A. 2003. Physical Risk-Taking: dangerous or endangered? Early Years 23(1): 35-43.

Sutton-Smith, B. 1997. The ambiguity of play. Cambridge, MA: Harvard University Press.

Tapscott, D. 1998. Growing up digital: The rise of the Net generation. New York: McGrawHill.

Toren, C. 2007. Sunday lunch in Fiji: continuity and transformation in ideas of the household. American Anthropologist 109(2): 285-295.

United Nations High Commissioner for Human Rights. 1989. UN Convention on the Rights of the Child (UNCRC). Geneva: Office of the United Nations High Commissioner for Human Rights.

Valentine, G. 2004. Public space and the culture of childhood: London. Ashgate

Waddington, S. 2000. Changing life in the towns of north Kildare. Irish Geography 33(1): 74-89.

Williams, S., and L. Williams. 2005. Space invaders: The negotiation of teenage boundaries through the mobile phone. The Sociological Review 53 (2): 314-331. 